\title{
Dilemas sobre futuro e escola: narrativas etnográficas de jovens estudantes
}

BORGES, Luís Paulo Cruz ${ }^{1}$

\section{RESUMO}

A relação dos jovens estudantes do Ensino Médio com o futuro e a escola é objeto de estudo do presente artigo. Pauta-se na abordagem etnográfica, situada na fronteira entre a antropologia e a educação. Foram utilizados o caderno de campo, notas etnográficas, entrevistas, fotografias, observação participante e produções textuais como formas de apreender um recorte da realidade social. Articulam-se categorias como conhecimento escolar e juventudes privilegiando uma abordagem pós-crítica e pós-colonial para pensar o futuro e seus sujeitos. Opera-se numa lógica de que há uma polifonia nas vozes discentes que podem ser escutadas, como forma de uma produção curricular, pensando os dissensos como caminhos possíveis, a partir da ideia de juventudes em trânsito, abordando a relação dos jovens com seus processos educacionais tendo como horizonte o futuro. Este artigo apresenta a ideia do futuro como uma categoria etnográfica, sendo esta uma dimensão criadora dos modos de subjetivação e diferença.

Futuro/escola. Etnografia. Jovens.

\section{Dilemmas about future and school: ethnographic narratives of young students}

\section{ABSTRACT}

The relationship of young high school students with the future and the school is the object of study of this article. It is based on the ethnographic approach, situated on the border between anthropology and education. Thus, the field notebook, ethnographic notes, interviews, photographs, participant observation and textual productions were used as ways of apprehending a cut of social reality. Categories such as school knowledge and youths are articulated, favoring a post-critical and post-colonial approach to thinking about the future and its subjects. It operates on the logic that there is a polyphony in student voices that can be heard as a form of curriculum production thinking dissent as possible paths from the idea of youths in

${ }^{1}$ Doutor em Educação Universidade do Estado do Rio de Janeiro Professor do Instituto de Aplicação Fernando Rodrigues da Silveira da Universidade do Estado do Rio de Janeiro (CApUERJ). (ProPEd/UERJ). E-mail: borgesluispaulo@yahoo.com.br. Lattes: http://lattes.cnpq.br/0194486050835751. ORCID: https://orcid.org/0000-0002-2153-5229.

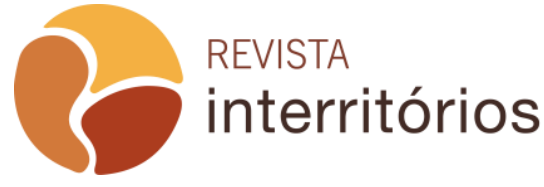

Interritórios | Revista de Educação Universidade Federal de Pernambuco, Caruaru, BRASIL | V.6 N.10 [2020] 
transit addressing the relationship of young people with their educational processes with the horizon future. This article presents the idea of the future as an ethnographic category and this is a creative dimension of the modes of subjectivation and difference.

Future/school. Ethnography. Young.

\section{Dilemas sobre el futuro y la escuela: narraciones etnográficas de jóvenes estudiantes}

\section{RESUMEN}

La relación de los jóvenes estudiantes de secundaria con el futuro y la escuela es el tema de este artículo. Se guía por el enfoque etnográfico, situado en la frontera entre antropología y educación. El cuaderno de campo, las notas etnográficas, las entrevistas, las fotografías, la observación participante y las producciones textuales se utilizaron como formas de comprender un resumen de la realidad social. Categorías como el conocimiento escolar y la juventud están articuladas, privilegiando un enfoque postcrítico y postcolonial para pensar sobre el futuro y sus temas. Funciona con la lógica de que existe una polifonía en las voces de los estudiantes que se puede escuchar, como una forma de producción curricular, pensando en la disidencia como posibles caminos, desde la idea de los jóvenes en tránsito, abordando la relación de los jóvenes con sus procesos educativos. mirando hacia el futuro Este artículo presenta la idea del futuro como una categoría etnográfica, que es una dimensión creativa de los modos de subjetividad y diferencia.

Futuro / escuela. Etnografía. Gente joven.

\section{Dilemmi sul futuro e sulla scuola: narrazioni etnografiche di giovani studenti}

\section{SINTESE}

La relazione dei giovani studenti delle scuole superiori con il futuro e la scuola è l'oggetto di questo articolo. Ė guidato dall'approccio etnografico, situato al confine tra antropologia ed educazione. II quaderno di campo, le note etnografiche, le interviste, le fotografie, l'osservazione dei partecipanti e le produzioni testuali sono stati usati come modi per comprendere uno schema della realtà sociale. Categorie come la conoscenza scolastica e la gioventù sono articolate, privilegiando un approccio post-critico e post-coloniale a pensare al futuro e alle sue materie. Funziona secondo una logica secondo cui esiste una polifonia nelle voci degli 
studenti che può essere ascoltata, come una forma di produzione curricolare, pensando al dissenso come possibili percorsi, dall'idea dei giovani in transito, affrontando il rapporto dei giovani con i loro processi educativi guardando al futuro. Questo articolo presenta l'idea del futuro come una categoria etnografica, che è una dimensione creativa delle modalità di soggettività e differenza.

\section{Futuro / scuola. Etnografia. Giovani.}

\section{O estudo}

A temática desse artigo está inserida nos dados da pesquisa foi desenvolvida durante o período de sete meses (entre os anos de 2014 e 2018) junto a alunos e alunas do Ensino Médio de uma escola pública no Estado do Rio de Janeiro, em Nova Iguaçu. Alunos estes que carregam o qualificador de jovens e de sujeitos da pesquisa que também fazem parte das juventudes do país. Foram observadas duas turmas, de $2^{\circ}$ e $3^{\circ}$ anos a partir da ideia de colaboração na pesquisa etnográfica. Ação pautada na relação entre confiança e ética de pesquisadores e professores (MATTOS, 1994).

São os participantes da pesquisa os/as jovens estudantes, alunos e alunas entre 16 e 19 anos; afrodescendentes em sua grande maioria; oriundos das classes populares, sendo moradores da Baixada Fluminense, região com sérias questões sociais e econômicas, por exemplo, falta de estrutura cultural, como teatros e falta de saneamento básico, como água e esgoto.

Boa parte dos jovens-estudantes se declararam cristãos do segmento protestante, sobretudo, os neopentecostais ${ }^{2}$. Jovens que vivem uma juventude pautada na incerteza do mundo atual, um tipo de incerteza que se reflete em diversos fluxos culturais pautados na diferença (APPADURAI, 2009). Entende-se aqui, que tal juventude está em trânsito, ou seja, integra um grupo social que desempenha um papel em via de mão dupla: i) jovens que são enquadrados como estudantes e por isso mesmo carregam um entendimento pautado no padrão, no uniforme e na expectativa de algo; ii) uma juventude que não cabe em si, mas que, extrapolando suas próprias demarcações se mostra presente no dia a dia da vida escolar com tensões, tráfegos e movimentos, sendo jovens estudantes, ou mesmo, estudantes jovens.

Podemos pensar que o etnógrafo "se move num campo de gêneros

\footnotetext{
${ }^{2}$ O neopentecostalismo pode ser considerado um movimento dissidente dos evangélicos que congregam denominações oriundas do pentecostalismo clássico ou mesmo das igrejas cristãs tradicionais, tais como as batistas, as metodistas, etc. Surgiram em meados dos anos 1970, algumas décadas após o movimento pentecostal do início do século XX.
} 
disciplinares difusos, ou imprecisos" (CARVALHO, 2001, p. 109). A etnografia como abordagem de investigação científica traz contribuições para o campo das pesquisas que se interessam pelo estudo das desigualdades e exclusões sociais, de acordo com Mattos (2002), por preocupar-se com uma análise holística da cultura, ou seja, a cultura não é vista como um mero reflexo de forças estruturais da sociedade, mas como um sistema de significados e significantes mediadores entre as estruturas sociais e a ação humana. $E$ também, por compreender os sujeitos sociais com uma participação ativa e dinâmica no processo modificador das próprias estruturas sociais.

É preciso compreender que o campo educacional tentando assumir "[...] pontos de vista da Antropologia tenta, antes de tudo, delimitar fronteiras que marcam ambas as áreas e que não podem simplesmente ser dissolvidas, mas repensadas no sentido da articulação que mantém suas identidades e diferenças" (PEREIRA-TOSTA, 2011, p. 428). Dessa maneira, a escola torna-se lócus profícuo de análise e produção de sentidos sobre os mundos que lá habitam, gerando idiossincrasias necessárias no processo de produção de conhecimento.

Assumimos a perspectiva da abordagem etnográfica e a colaboração em pesquisa. A etnografia, enquanto abordagem voltada para a apreensão do conhecimento e do entendimento do sujeito pesquisado sobre seus "fazeres diários", tornou-se uma ferramenta importante para fazer sentido sobre a realidade estudada. A etnografia, enquanto preponderantemente derivada dos paradigmas interpretativo, ecológico e interacionista-simbólico, pode conferir à pesquisa um aparato teórico que vai além do mecanismo de fazer pesquisa, isto é, de uma metodologia científica derivada da pesquisa qualitativa.

Foi assim que o olhar dos alunos e alunas da escola foi se entrecruzando com o olhar do pesquisador. Foram olhares que, se chocando, foram produzindo percepções de mundo. Segundo Lüdke e André (1986), o pesquisador ainda é o principal responsável pela feitura e pela organização das informações investigadas no âmbito da pesquisa e, por isso, guia o olhar na percepção do que deseja investigar. A partir do olhar dos estudantes que participaram na pesquisa, há uma complexidade posta às formas de compreensão através do eu e do Outro.

As vozes dos participantes da pesquisa são evocadas, mas não em um sentido de ilustração, ou seja, de mera corroboração para algo já existente. Antes de tudo, parte-se de tais vozes para se construir uma teorização com e para os jovens que estão presentes na escola (MATTOS; ALVES, 2015), gerando uma teorização de como os jovens-estudantes se relacionam com o conhecimento escolar.

As análises ocorreram pela conceituação do conteúdo como um conjunto de

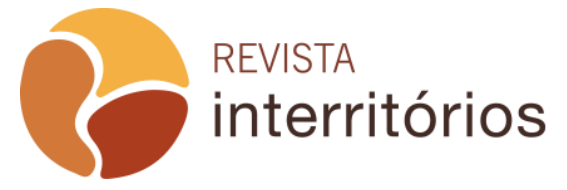

Interritórios | Revista de Educação Universidade Federal de Pernambuco, Caruaru, BRASIL | V.6 N.10 [2020] 
"técnicas de análise das comunicações visando obter, por procedimentos sistemáticos e objetivos de descrição do conteúdo das mensagens (quantitativos ou não) que permitam a inferência de conhecimentos relativos às condições de produção/recepção (variáveis inferidas) destas mensagens" (BARDIN, 2011, p. 46). De forma, a i) preparar as informações; ii) unitarização ou transformação do conteúdo em unidades; iii) categorização ou classificação das unidades em categorias; iv) descrição; v) interpretação.

Enquanto doadora de sentido às atividades cotidianas, a etnografia impõe ao pesquisador uma posição de intérprete privilegiado dos sujeitos que apresentam os sentidos sobre as suas vidas. Ao participante, a etnografia propicia um distanciamento da realidade diária que muitas vezes lhe é invisível pelo caráter rotineiro das ações. Isto oportuniza a reflexividade e relativiza o sentido imediato dado a ação. Em colaboração com a pesquisadora os alunos e a professora desenvolveram, além do sentido mais frequente que já possuem sobre essas ações. Neste momento, um novo sentido, mais elaborado e problematizado, é criado dando uma dimensão crítica à realidade e possibilitando a sua reelaboração significativa.

No próximo tópico abordaremos as vozes dos jovens-estudantes da escola pesquisa sobre o futuro e a escola.

\section{Vozes em contradição sobre a escola, o futuro e as juventudes}

A escola tem futuro? Tal pergunta é problematizada nesse estudo pautado nos autores, Costa (2007) e Canário (2006), que trazem ao debate à centralidade da escola na vida moderna, ou mesmo, pós-moderna. Uma questão com múltiplas respostas possíveis. Contudo, coloca-se relevo, aqui, não respostas, mas a própria pergunta em sua relação escola-futuro a partir do olhar e das vozes juvenis.

A primeira autora, Costa (2007), em diálogo com diferentes autores do campo educacional no Brasil, argumenta que a escola, nascida como instituição do século $X V$, vem enfrentando, ao longo dos séculos, um conjunto de transformações sociais que perduram hoje numa reflexão acerca de ser: i) uma escola que assegura a todos a formação cultural e científica; ii) uma escola que tem a função de garantir justiça social; iii) uma escola que é arrolada no cotidiano; iv) uma escola que deve garantir a manutenção das conquistas da modernidade; v) uma escola que garanta direitos à educação; vi) uma escola que nos ajude a formar sujeitos numa perspectiva cidadã. Embora não haja um consenso sobre o lugar em que chegará a instituição escolar, há uma compreensão de que a escola parece ser, também hoje, algo central na vida das sociedades e das pessoas. Por fim, um objetivo ainda parece prevalecer: o ideário da razão cartesiana proposto no século XV que deve ser

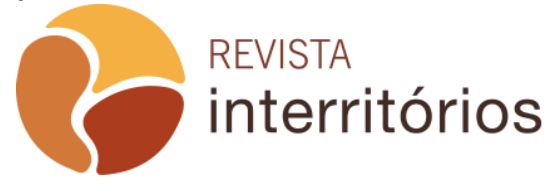

Interritórios | Revista de Educação Universidade Federal de Pernambuco, Caruaru, BRASIL | V.6 N.10 [2020] 
transmitido aos sujeitos escolares. Ao mesmo tempo, esse ideário se imbrica na representação social pós-industrial de que a escola preparava para o futuro do trabalho.

O segundo autor, Canário (2006), indica que não é possível prever o futuro da escola. Todavia, é possível problematizar a sua construção temporal numa perspectiva de reflexão crítica para que o mesmo futuro seja resultado de uma construção pautada num projeto de sociedade. Ou seja, para pensar e transformar a escola é preciso que i) se pense a escola fora dos muros escolares; ii) que o trabalho escolar seja o trabalho de aprender a viver uma construção; iii) que se pense a escola em consonância com os movimentos sociais. Em suma, é preciso assumir uma postura crítica para se pensar a "crise da escola" viabilizando uma mudança de mundo.

A ideia de futuro, ainda durante a pesquisa de campo, emerge em uma dupla transitividade: o futuro como temporalidade e o futuro como emergência e imaginação das relações sociais dos jovens com o conhecimento escolar e com a própria escola. Os sentidos de futuro tornam-se categoria no campo etnográfico, precisamente por se relacionarem à imaginação, criação, narrativa e subjetividade. Aguça-se o olhar para as muitas vias investigativas que emergem dos sentidos de futuro, pensando, a partir dos jovens-estudantes do Ensino Médio, a ideia de presentificação da vida cotidiana. O futuro no arcabouço etnográfico traçado pelos jovens-estudantes se enuncia como o hoje e o agora, mas também o amanhã, destacando a simultaneidade temporal e espacial do sujeito no mundo.

O presente, a materialidade, o imediatismo, a rapidez, a tecnologia etc., passam a ser temáticas relacionadas ao conhecimento, pois interferem na relação estudante-conhecimento escolar. Nas palavras de Pais (2006), há uma desfuturização do futuro, ou um investimento crescente no presente, assumindo uma dicotomia: presente versus futuro. Entretanto, discordando do autor, pode-se perceber que os projetos de futuros dos jovens-estudantes, ora não existem, ora assumem centralidade no discurso juvenil, quando não assumem, concomitantemente, tal ambivalência.

Não há um único movimento. Antes de tudo, há movimentos, no plural, que indicam a dupla transitividade do futuro como categoria na vida do jovem-estudante do Ensino Médio da escola pesquisada. São instâncias de negociação que perpassam pelas relações, não somente existentes na escola, mas no WhatsApp, no Facebook, no baile funk, no grafite, na igreja etc.

De acordo com dados da pesquisa, foi questionado aos estudantes o que esperar do futuro. Suas narrativas, a partir das entrevistas etnográficas, revelam emergências possíveis do que desejam os alunos e alunas do Ensino Médio.

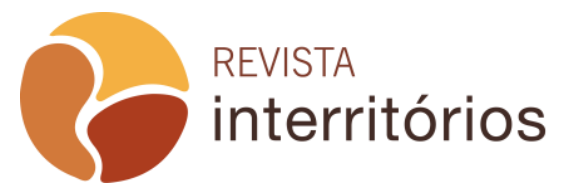

Interritórios | Revista de Educação Universidade Federal de Pernambuco, Caruaru, BRASIL | V.6 N.10 [2020] 
Revelam subjetividades e evidenciam uma reflexividade da condição juvenil, como demonstram os oito trechos de fala abaixo. São reflexões postas para que o leitor também possa fazer suas leituras e interpretações, indicando assim um percurso metodológico pautado na etnografia.

\section{E agora, o que espero do futuro?}

Que se as coisas forem muito boas posso repassar e se não forem boas refletir e conversar com outras pessoas. Eu espero do futuro que possa me formar e ter um ótimo emprego (Aluna Ayla).

Ter uma visão diferente, espero que no futuro as coisas melhorem não só para mim, mas para todos (Aluna Odara).

O importante é absorver todo bom conhecimento e continuar aprendendo cada vez mais (Aluno Criolo).

É importante que mesmo conhecendo tudo isso, você tenha caráter, ninguém chega a lugar algum sem ele, pode até chegar mas um dia será prejudicado. Eu espero um futuro melhor que os dos meus pais, não que seja ruim, mas eu espero fazer um curso superior, me formar, ter meus próprios bens (Aluno Daomé).

Que seja melhor do que o presente, ou o passado (Aluno Emicida).

O importante é filtrar o conhecimento útil e aplicar no futuro em prol de um bem comum (Aluno Luiza).

É muito importante adquirir experiência. E o futuro espero que eu realize todos os desejos e sonhos (Aluno Mahin).

O aumento da cultura e o conhecimento que adquiri nestes locais. Que eu possa aprender mais ainda sobre a nossa sociedade (Aluna Bell).

O tempo parece ser um caminho possível para a compreensão das relações sociais, por exemplo, com a explicação: "espero me formar e ter um emprego". Porém, há subjetividades latentes que precisam ser compreendidas ao propor uma forma de pensamento em que o sujeito se relaciona com o Outro e consigo mesmo. O tempo passa ser, então, imaginação de um futuro possível e também desejo de realidade material concreta, necessária e palpável. Seriam o futuro e o tempo formas de conhecimento silenciadas na escola?

As falas acima revelam que é possível um empreendimento necessário na compreensão de que o futuro seja espaço de imaginação e contradição, "Que seja melhor do que o presente, ou o passado", conforme fala de um aluno. Talvez, traga

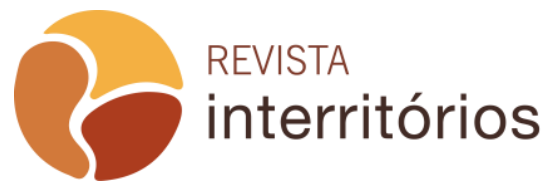

Interritórios | Revista de Educação Universidade Federal de Pernambuco, Caruaru, BRASIL | V.6 N.10 [2020] 
um quê de transformação da realidade social em que estes jovens-estudantes do Ensino Médio estejam inseridos. Sobretudo, pensando a realidade da escola pesquisada em Nova Iguaçu, Baixada Fluminense, no Estado do Rio de Janeiro. Um estado que vem sofrendo com políticas de governo marcados pela corrupção e pela negligência com o serviço público.

Abaixo segue um quadro organizado e analisado com as temáticas e vozes discentes sobre o futuro. Em nosso caso, entendemos que a categorização se dá por agrupamento das temáticas, o que pressupõe uma organização que "estuda os conteúdos por núcleos de sentido e tematiza os depoimentos" (FONTOURA, 2008, p. 138).

As temáticas utilizam-se das relações de sentidos que os sujeitos da pesquisa dão ao corpus de análises. Nesta perspectiva, as "temáticas são sempre uma constante no estudo" (FIGUEIREDO, 1999, p. 49) embora, em etnografia, a falta de recorrência também possa ser considerada uma temática. É pelo olhar do etnógrafo, que vê e registra densamente a cena ocorrida e que a julga como relevante ao estudo, que se constroem as temáticas atípicas (FONTOURA, 2008).

Reafirmando, mais uma vez, o princípio etnográfico de ordenação e reordenação de mundos, olhares e perspectivas que são necessárias às articulações empíricas para que estas ganhem significados e possam extrapolar ou transbordar o cientificismo a partir de uma versão da realidade. Assim, as leituras e compreensões de análises do pesquisador são fundamentais no processo de entrecruzamento e organização das categorias temáticas que emergem no campo com seus interlocutores; neste caso, os jovens-estudantes, que se tornarão teorizações.

\section{Quadro - Vozes sobre o futuro}

\begin{tabular}{|c|l|}
\hline \multicolumn{1}{|c|}{ Temáticas } & \multicolumn{1}{c|}{ Vozes dos estudantes } \\
\hline Trabalho, formação e profissão & $\begin{array}{l}\text { Que se as coisas forem muito boas posso repassar e se não forem } \\
\text { boas refletir e conversar com outras pessoas. Eu espero do futuro } \\
\text { que possa me formar e ter um ótimo emprego (Aluna Ayla). } \\
\text { Eu espero um futuro melhor que os dos meus país, não que seja } \\
\text { ruim, mas eu espero fazer um curso superior, me formar, ter meus } \\
\text { próprios bens (Aluno Daomé). }\end{array}$ \\
\hline Conhecer e aprender & $\begin{array}{l}\text { O importante é absorver todo bom conhecimento e continuar } \\
\text { aprendendo cada vez mais (Aluno Criolo). } \\
\text { O importante é filtrar o conhecimento útil e aplicar no futuro em prol } \\
\text { de um bem comum (Aluno Luiza). } \\
\text { O aumento da cultura e o conhecimento que adquiri nestes locais. } \\
\text { Que eu possa aprender mais ainda sobre a nossa sociedade }\end{array}$ \\
\hline
\end{tabular}




\begin{tabular}{|c|l|}
\hline & (Aluna Bell) \\
\hline Esperança em algo melhor & $\begin{array}{l}\text { Ter uma visão diferente, espero que no futuro as coisas melhorem } \\
\text { não só para mim, mas para todos (Aluna Bianca). } \\
\text { Que seja melhor do que o presente ou o passado (Aluno Emicida). }\end{array}$ \\
\hline Experiência, sonho e desejos & $\begin{array}{l}\text { É muito importante adquirir experiência. E o futuro espero que eu } \\
\text { realize todos os desejos e sonhos (Aluno Mahin). }\end{array}$ \\
\hline
\end{tabular}

Fonte: Borges, 2017.

Depreende-se do quadro que: i) há uma relação entre as subcategorias trabalho, formação e profissão numa projeção de futuro; ii) a busca por conhecer e aprender também está interligada ao futuro; iii) que a temporalidade traz esperança em algo melhor, um mundo melhor; iv) o futuro como lugar da experiência, sonho e desejo.

Tomando a relação trabalho-formação-profissão, encontramos narrativas sobre como o futuro pode gerar uma expectativa de se chegar à faculdade, universidade, curso técnico, enfim, à formação/trabalho como uma estabilidade, mesmo que provisória, para a juventude que está em trânsito. As quatro narrativas abaixo são das jovens-estudantes participantes da pesquisa, todas da $3^{a}$ série do Ensino Médio, que revelaram na produção textual o que esperam dos seus próprios futuros.

Para o meu futuro, depois da escola, faculdade de administração ou contabilidade. E senão der certo quero fazer faculdade de direito, mas quero começar de baixo, pois como minha mãe diz: "na vida temos que começar por baixo para crescer na vida" (Produção textual da aluna Rayla, 17 anos, $3^{\text {a }}$ série do E.M.).

E para o meu futuro eu pretendo estudar bastante, fazer faculdade de odontologia. Ter meu consultório, ter minha vida estabilizada, casar, ter filhos e no mais importante ser feliz (Produção textual da aluna Lara, 16 anos, $3^{\text {a }}$ série do E.M.).

Do futuro espero muito dinheiro, que eu me forme em pediatria, que consiga ajudar muitas pessoas, que eu possa comprar o que eu quiser, que não precise depender de ninguém pra nada (Produção textual da aluna Benta, 16 anos, $3^{\mathrm{a}}$ série do E.M.).

Terminar o $2^{\circ}$ grau (Ensino Médio) e fazer um técnico de administração, pois faculdade eu não penso em fazer. Mas também quero um dia fazer concurso público, investir em no meu futuro para um dia dar uma ótima educação para meus filhos e que um dia eles possam me olhar e saber que eles também são capazes de pensar que no futuro vale a pena (Produção textual da aluna Thamara, 17 anos, $3^{\mathrm{a}}$ série do E.M.). 
As narrativas indicam uma perspectiva de cursar uma faculdade: administração ou direito, odontologia e pediatria. Uma das alunas, Thamara, sinaliza que não pretende fazer faculdade, opta pelo curso técnico em administração. Rayla sinaliza que quer começar "por baixo". Contudo, já Lara evidencia "ter o próprio" consultório. Benta fala em ter muito dinheiro, ao mesmo tempo que pensa em "ajudar muitas pessoas". Por fim, Thamara relaciona seu futuro profissional ao dos seus pretensos filhos, "para um dia dar uma ótima educação para meus filhos".

Os textos das jovens estudantes omitiram as condições materiais necessárias que foram observadas na escola pesquisada. Não falam que inúmeras vezes faltaram professores, que as condições materiais da sala de aula e da escola eram parcas e que, em comparação, há um fosso no sistema de organização entre as escolas públicas e privadas, sobretudo, das escolas que estão à margem dos grandes centros, como é o caso da Escola Alvorada. Também não revelam os conteúdos ensinados, as metodologias adotadas pelos docentes e o não uso das tecnologias na sala de aula.

Retorna-se a Canário (2006) para se pensar que, ao longo dos séculos, a escola tinha uma função de escolarização ligada ao mundo do trabalho, sobretudo, as escolas de primeiras letras para as classes populares. $O$ modelo hegemônico escolar ganha destaque a partir do século XVIII que também é um modelo de socialização normativa. As reflexões das estudantes acima propõem que elas acreditam nessa escola, ou mesmo, acreditam que podem superar os percalços e galgar um curso superior ou técnico.

A relação trabalho, profissão e formação é tênue por abarcar, em si, contradições presentes na estrutura social em que vivemos. As desigualdades sociais presentes no dia a dia da população brasileira ganham relevo quando se pensa nas oportunidades ofertadas às classes populares.

As falas das quatro estudantes não revelam que a escola pesquisada é um microuniverso de desigualdades sociais que abarcam o todo presente na sociedade em que vivemos. Sobremaneira, focam em pensar a relação trabalho, profissão e formação entremeada pela ideia de futuro e revelando-se emblemática pelo contexto político e social em que se vive na atualidade e pelas questões práticas como a falta de professores, a falta de expedições, a falta de materiais e tantas outras faltas. Não se podem perder no horizonte as questões pautadas na materialidade da vida cotidiana.

No que condiz à busca por conhecer e aprender, tais relações estão baseadas também na ideia de práticas de estudo. O estudar ligado à escolarização. É o estudo que possibilitará um futuro diferente, aqui significando diferente como

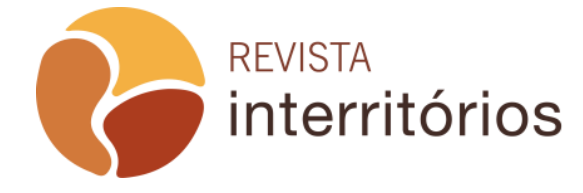

Interritórios | Revista de Educação Universidade Federal de Pernambuco, Caruaru, BRASIL | V.6 N.10 [2020] 
algo melhor para as estudantes. As três narrativas que se seguem são de alunas da $3^{a}$ série do Ensino Médio, apresentadas nas produções de texto, e sugerem o estudo como possibilidade de futuro em que se possa aprender mais.

Sou uma pessoa que não desiste fácil das coisas que eu quero, penso alto em um futuro brilhante e ter uma condição de vida boa. Se eu tiver que estudar minha vida toda para ser bem recompensada, eu estudarei. Quero fazer faculdade de engenharia civil, vou me esforçar pra fazer o ENEM para poder fazer faculdade que eu quero. Estou indecisa se me torno uma engenheira ou se faço concurso público que também é uma segunda opção. Sou esforçada e faço de tudo para conseguir o que quero (Produção textual da aluna Mariah, 16 anos, $3^{\mathrm{a}}$ série do E.M.).

É importante aprender para quando chegar mais à frente terminar e usar o que aprendemos para coisas da vida que vem e isso no ajudará no futuro para sermos o que quisermos ser, pessoas melhores (Produção textual da aluna Betina, 16 anos, $3^{a}$ série do E.M.).

Já para o meu futuro eu quero me dedicar bastante ao meu estudo esse ano para que eu possa passar no ENEM e conseguir uma bolsa na faculdade e dar uma vida melhor para minha família, ter uma condição melhor para dar aos meus filhos, um bom estudo, e não ter que passar pela mesma educação precária que eu tive que passar (Produção textual da aluna Jacy, 17 anos, $3^{a}$ série do E.M.).

Há diversos sentidos sobre estudar, sobretudo, quando este se relaciona ao vivido na escola. Todavia, Mariah afirma que "Se eu tiver que estudar minha vida toda para ser bem recompensada, eu estudarei”. Também um estudo ligado a uma recompensa, um retorno, ou mesmo, um investimento. Nesse sentido, Betina também diz isso: "aprendemos para coisas da vida que vem e isso nos ajudará no futuro". Jacy indica que precisa estudar para passar no Exame Nacional de Ensino Médio (ENEM). Interessante destacar que Jacy traz uma reflexão pontual sobre a escola: "ter uma condição melhor para dar aos meus filhos, um bom estudo, e não ter que passar pela mesma educação precária que eu tive que passar". Identificase a crítica social sobre a escola pública hoje, embora na forma de um escape à representação sólida do poder transformador da educação, sinalizando, assim, uma contradição.

As narrativas das jovens estudantes revelam, então, uma autodeterminação presente em um ideal de estudar mais para ter condições melhores de vida. Então, é possível compreender o conhecer/aprender como uma estratégia, uma mola propulsora para algo, um objetivo de ação dado ao que se vive na escola. Evocase o conceito de resiliência como forma para se pensar as identidades mobilizadas

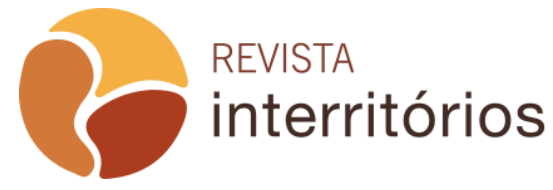

Interritórios | Revista de Educação Universidade Federal de Pernambuco, Caruaru, BRASIL | V.6 N.10 [2020] 
pelo alunado na escola (CASTRO, 2015). Resiliência esta que, rasura o quadro de possibilidade concreta de sucesso pela escola, extrapolando o valor e a crença nos estudos e abrindo-se uma porta na direção de uma nova escola que se enseja no futuro.

A partir da reflexão acima, na voz da aluna Jacy, destaca-se o pensamento de Pinar (2016), indicando que o currículo é uma conversa complicada e é essa complicação que Jacy evidencia em sua narrativa. A precariedade da educação que ela viveu gerou uma forma de reflexividade produzida nessa mesma escola precária que ela critica. "Essa conversa com os outros é complicada devido a nossa individualidade e a deles, e suas diferentes localizações" (PINAR, 2016, p. 21).

A individualidade traz uma perspectiva de relação entre o conhecer, aprender e o futuro marcada por uma subjetividade, ou seja, pelo percurso individual de cada sujeito. Embora Betina e Mariah não evidenciem tal dimensão vivendo o mesmo ano de escolaridade e estando na mesma escola, é sobre o olhar da Jacy que se desencadeia uma reflexão acerca das subjetividades, "marcada pela cultura, nacionalidade, pela historicidade" de cada um (PINAR, 2016, p. 28).

Nesse sentido, é preciso perceber que "descobrir o futuro, então, significa voltar ao passado, não instrumentalizar o presente" (PINAR, 2016, p. 30). Então, é preciso perceber nas falas arroladas acima que o futuro se desdobra, ou seja, segue individualidades que são ressignificadas pela experiência de cada um, operando numa lógica da diferença, pelo vivido também no âmbito escolar. A relação de conhecer e aprender, então, é estabelecida na própria relação com o mundo e nas complicações advindas dele.

São essas relações entre o conhecer e aprender que geram novas possibilidades de compreensão do papel social da escola, presente hoje na vida de seus sujeitos. A escola pesquisada, apesar das condições parcas, ainda se apresenta, de acordo com as falas das estudantes, como uma possibilidade de lugar de conhecimento e aprendizagem. Mas seria somente a escola ocupando tal lugar?

A esperança em algo melhor, ou pior, sobre o mundo, é o terceiro tópico de categoria. As produções textuais indicam que o contexto político também faz parte do horizonte dos estudantes, como é o caso do aluno Luiz Gama. Há um desejo de que o futuro seja o espaço-tempo da possibilidade de um mundo melhor, segundo Sarah. Por fim, Leona evidencia a tensão indivíduo-sociedade ao afirmar que "quer mudar a sociedade, mas a sociedade não quer mudar". Os quatro textos abaixo consubstanciam uma ideia de relação entre a esperança, ou mesmo, a busca por mudanças, pelo inusitado de um mundo que ainda causa frustações e desesperança. 
Eu espero coisas novas para o futuro com esse dia a dia cheio de surpresas, procuro sempre me preparar para o pior e o melhor, mas com essa grande discussão na política brasileira está por vir sempre o pior, ou seja, a educação no Brasil sempre irá de mal a pior (Produção textual do aluno Luiz Gama, 17 anos, $2^{a}$ série do E.M.).

Meu amanhã eu faço através da minha escolha e pra falar a verdade todo lugar se aprende alguma coisa, seja na rua, em casa. Então, eu digo que sou uma audaciosa, porque acredito no melhor e não qualquer coisa que me tire do trilho da vida (Produção textual da aluna Jurema, 17 anos, da $3^{a}$ série do E.M.).

Para o futuro eu espero coisas novas, coisas diferentes, coisas surpreendentes que possam fazer o mundo melhor ou até mesmo melhorar nem que seja um pouco, acima de tudo, devemos respeitar uns aos outros. (Produção textual da aluna Sarah, 17 anos, $3^{\text {a }}$ série do E.M.).

O meu futuro pode não ser muito bom, pois eu quero mudar a sociedade, mas a sociedade não quer mudar. $\mathrm{E}$ o meu medo de crescer com a ignorância me apavora, pois, o mundo está cheio da ignorância e de forma bem ilimitada. Mas eu creio que até lá eu vou estar em um trabalho acordando cedo e trabalhando todo dia e vivendo para isso, pois essa é a regra, a regra é diversão, trabalho, deveres, direito e dinheiro. $\mathrm{E}$ isso gira entorno de mim (Produção textual da aluna Leona, 16 anos, $3^{\mathrm{a}}$ série do $\mathrm{E}$. M.).

Depreende-se das narrativas acima que há um desejo de melhora, sobretudo, se comparado à situação atual que cada jovem-estudante vive. Esperança calcada num futuro como surpresa, continuação do trilho da vida, novidade e ação individual. Concomitantemente, tem-se o receio de algo pior, que Ihes tire do trilho/caminho certo, além o medo de lidar com a ignorância dos outros.

Os textos, então, são reveladores da contradição posta à realidade social de cada estudante. São as formas de percepção que cada um apresenta da vida, sobretudo, do lugar de partida social de cada um. Aqui se indica que a Baixada Fluminense é um lugar de partida da realidade social para leitura de mundo desses jovens-estudantes.

Bhabha (2011) sinaliza que os horizontes podem ser constantes fricções através da cultura. Aqui, retoma-se a ideia da "cultura como diferença, [que] nos habilitará perceber a articulação da fronteira, do espaço sem raízes..." (BHABHA, 2011, p. 83).

O valor temporal que cada jovem-estudante evidencia traz consigo uma construção do espaço-tempo da esperança que eles desejam para si, sem raízes. Tampouco negam o olhar para suas realidades sociais, indicando assim que há

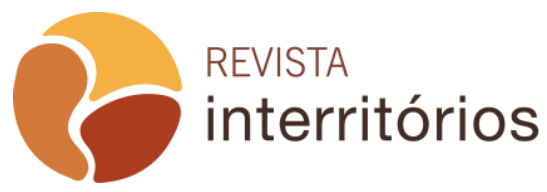

Interritórios | Revista de Educação Universidade Federal de Pernambuco, Caruaru, BRASIL | V.6 N.10 [2020] 
medo, conflitos etc. Há um desdobramento das suas vozes e imaginário para construção da própria visão de si e do mundo. Destaca-se o lugar da educação - "a educação no Brasil sempre irá mal" - em uma compreensão de que o contexto externo à escola também se compõe no cenário interno a ela, ou seja, a esperança dessa juventude em trânsito também se constrói numa via de mão dupla de ambiguidades, ora positiva, ora negativa, mas sempre em movimento.

As questões arroladas acima sinalizam para o entendimento de uma demanda sobre o papel da escola na construção da esperança. A esperança no futuro, segundo Bhabha (2011), também é a possibilidade da emergência de novas formas de compreensão das relações sociais. Contraditoriamente, as palavras de Leona sinalizam o lugar do medo: " $E$ o medo de crescer com a ignorância me apavora, pois, o mundo está cheio de ignorância e de forma bem ilimitada". Contudo, é o medo da ignorância que disputa sentido, aqui, com a ideia de conhecimento. Talvez resida nessa relação, ignorância versus conhecimento, o desafio da escola moderna presente nos dias de hoje, na medida em que se compreende a ignorância, não como um espaço-tempo vazio de saber, mas se tentando perceber quais sentidos damos à ignorância, ou mesmo, ao ignorante, no ambiente escolar.

Por fim, há o futuro como lugar da experiência, dos sonhos e desejos. As falas abaixo, de jovens-estudantes da $3^{\mathrm{a}}$ série do Ensino Médio, indicam a ideia de futuro como algo temporal, "o futuro está sempre no amanhã". E também relacionado ao desejo de mudança, "construindo minha vida não nos padrões da sociedade". Ainda, tem-se na fala de um estudante o destaque para a relação experiência, desejos e sonhos: "É muito importante adquirir experiência. E no futuro, espero que eu realize todos os desejos e sonhos" (Aluno Gael, da $2^{\mathrm{a}}$ série do Ensino Médio, em entrevista etnográfica).

O futuro está sempre no amanhã, o amanhã somente a Deus pertence e o ser humano tem o dever de viver o hoje, mas todo ser humano tem um sonho e esse sonho está sempre no futuro. $E$ espero que no futuro eu tenha minha família, minha mulher, meus filhos e uma vida estável (Produção textual do aluno Martin, 17 anos, e da $3^{\text {a }}$ série do E.M.).

Eu espero que eu esteja na polícia, longe de Nova Iguaçu, construindo minha vida não nos padrões da sociedade, mas sim nos padrões que eu possa fazer da minha coroa uma rainha (Produção textual da aluna Mística, 18 anos, $3^{a}$ série do E.M.).

As falas acima indicam, possivelmente, a busca por desejos e sonhos que, permeados de novos sentidos, são entrelaçados à vida: ter uma família, ser policial, 
ser rainha de si. Questiona-se, então, o lugar da escola dentro dessas expectativas. A fala abaixo, da aluna Karol, da $2^{\mathrm{a}}$ série, indica algo.

Entrevistador: você acha que a escola tem futuro?

Karol: acho, porque a escola é essencial na nossa vida. Você estudar e ter determinação. Vou estudar e aprender, eu quero isso pra mim. Então a escola tem que ficar ligada no futuro dos jovens e dos adolescentes. Porque não tem outro caminho, você tentar fazer outras coisas, mas senão tivesse o segundo grau? ...

A aluna indica que é preciso ter determinação, além de estudar e aprender. $\mathrm{O}$ desejo que ela detém para si. Contudo, pontua que a escola precisa "ficar ligada no futuro dos jovens e dos adolescentes", já que não há outro caminho. Seria essa a vida de mão única presente na sociedade de hoje: a escola precisa dialogar com os seus estudantes? Ou seja, não existe um diálogo presente e possível nessa relação (escola-estudantes)? O segundo grau, hoje Ensino Médio, se tornou um campo de disputas presentes no dia a dia das políticas, mas também um campo de disputa vivo na própria instituição: o que querem os estudantes com a escola? E o que querem as escolas com seus estudantes?

\section{À guisa de conclusão}

Desse episódio fica claro que a pesquisa de campo não tem momento certo para começar e acabar. Esses momentos são arbitrários por definição e dependem, hoje que abandonamos as grandes travessias para ilhas isoladas e exóticas, da potencialidade de estranhamento, do insólito da experiência, da necessidade de examinar por que alguns eventos, vividos ou observados, nos surpreendem. E é assim que nos tornamos agentes na etnografia, não apenas como investigadores, mas nativos/etnógrafos. Essa dimensão incita ao questionamento da etnografia como método (PEIRANO, 2014, p. 379).

Bhabha (2011) sinaliza que o futuro se torna uma questão social aberta, uma vez que tal categoria é um interstício que emerge do entrelugar do passado com o presente. A disputa pelo futuro também pode ser a disputa pela identidade de si. Por uma subjetividade que afeta e mobiliza a juventude em trânsito no espaçotempo da escola.

O passado e o presente, tão massacrados pelas crises e guerras que trazem uma imagem turva do tempo. O futuro surge como possibilidade de esperança, tal qual como evidenciado pelo estudante Martin, sobretudo, esperança em algo 
estável, melhor. Sabe-se que muito das experiências na escola vão se estender para outras relações vida afora. A possibilidade de estar em grupo, respeitar as individualidades assim como a coletividade, entender e cumprir normas, horários, adequar o comportamento, os modos de falar, são alguns das normas que vão sendo incorporadas ao longo da vida escolar. Esses traços integram a memória que os alunos guardam escola. Essas memórias são constantemente revividas, relembradas e reconhecidas para dar conta das adversidades que se impõe entre o sonho e a realidade ou aquilo que a escola leva a acreditar para que anos após anos permaneça-se lutando contra as situações que contingenciam as escolhas acadêmicas e profissionais dos alunos.

É nessa projeção de si e do mundo que se destaca a relação dos jovensestudantes com o conhecimento proposto pela escola. Uma relação que ocorre de forma tênue, talvez pela impossibilidade do diálogo, como já mencionado pela aluna Karol, mas que carrega sentidos para o entendimento de que tipo de conhecimento os estudantes desejam ter experiência: "Espero um futuro com mais oportunidades e sem diferenças de raças" (Aluna Joana, $2^{\mathrm{a}}$ série do Ensino Médio em entrevista etnográfica). A racialidade das identidades existentes na sala de aula, seria uma forma de reimaginação cultural do conhecimento escolar?

O desejo de um futuro com mais oportunidades e sem desigualdades raciais, talvez seja um indicativo das fronteiras que a escola precisará ultrapassar para se pensar como instituição sob rasura. A escola moderna está imersa numa arena em disputas de poder e saber que estão relacionadas a mudanças e transformações modernas e pós-modernas. $O$ debate, fraturado e não superado, resiste nas vozes discentes.

Ao fim e ao cabo, as categorias definidas na pesquisa e os fragmentos das vinhetas etnográficas analisados aqui, sustentam os resultados desse estudo ao relacionar os sentidos produzidos pelos jovens, alunos e alunas, com o conhecimento escolar numa perspectiva de pensar o futuro. Tais questões nos fazem refletir no lugar de pertencimento que se vive no dia a dia da escola e da resiliência que os alunos criam ao se relacionarem com a instituição (CASTRO, 2011). Assim ensejamos na construção de uma teorização em defesa da escola como lugar de produção de conhecimento num processo investigativo que seja capaz de apreender sentidos possíveis à pesquisa educacional.

\section{REFERÊNCIAS}

APPADURAI, A. O medo do pequeno número: ensaio sobre a geografia da raiva. São Paulo: Ed. Iluminuras: Itaú Cultural, 2009.

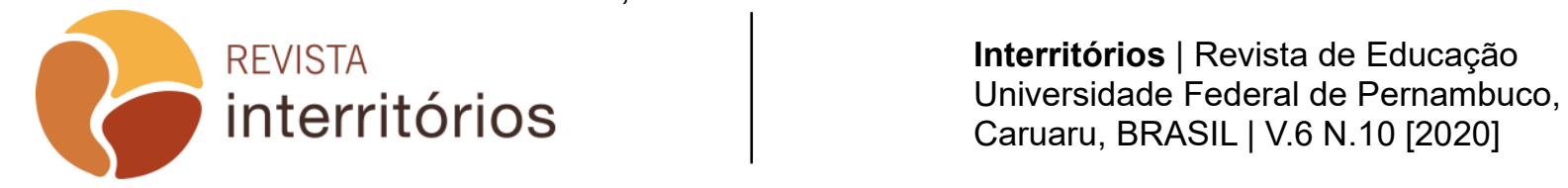


BARDIN, Laurence. Análise de conteúdo. São Paulo: Edições 70, 2011.

BHABHA, H. O Bazar Global e o Clube dos Cavaleiros Ingleses. Rio de Janeiro: Editora Rocco, 2011.

BORGES, L.P.C. O futuro da escola: uma etnografia sobre a relação dos jovens com o conhecimento escolar. 2018. 151 f. Tese (Doutorado em Educação) - Faculdade de Educação, Universidade do Estado do Rio de Janeiro, Rio de Janeiro, 2018.

CANÁRIO, R. A escola tem futuro? das promessas às incertezas. Porto Alegre: Artmed, 2006.

CARVALHO, J. J. O olhar etnográfico e a voz subalterna. Revista Horizontes Antropológicos, Porto Alegre, ano 07, n. 15, p. 107-147, 2001.

CASTRO, P. A de. Tornar-se aluno: identidade e pertencimento - um estudo etnográfico. 2011. 157f. Tese (Doutorado em Educação) - Faculdade de Educação, Universidade do Estado do Rio de Janeiro, Rio de Janeiro, 2011, p. 158.

COSTA, M.V. A escola tem futuro? 2 ed. Rio de Janeiro: Lamparina, 2007.

FIGUEIREDO, I de L. Procedimentos de tematização e figuratização na produção textual de alunos de terceiro grau. Revista do GELNE. Ano 01, n. 01, p. 49-51, 1999.

FONTOURA, H. A. Formando Professores que aprendem a partir dos relatos: uma experiência da Faculdade de Formação de Professores (FFP) da UERJ. Revista da FAEEBA - Educação e Contemporaneidade, Salvador, vol. 17, n. 29, p. 137-146, 2008.

LÜDKE, M.; ANDRÉ, M. E. D. A. Pesquisa em Educação: abordagens qualitativas. São Paulo, EPU, 1986.

MATTOS, C. L. G de. Etnografia crítica de sala de aula: o professor pesquisador e o pesquisador professor em colaboração. 17ª REUNIÃO ANUAL DA ANPED, Caxambu/MG, 1994.

MATTOS, C. L. G de. (coord.) Imagens da Exclusão. Projeto de Pesquisa. Rio de Janeiro, Departamento de Educação, UERJ, 2002.

MATTOS, C. L. G. ALVES, W. B. Outros saberes sobre a escola: a voz do aluno na pesquisa em educação. In: Maria do Socorro Lucena Lima; Maria Marina Dias Cavalcante; José Albio Morreira de Sales; Isabel Maria Sabino de Farias. (Org.). Didática e prática de ensino na relação com a escola. 1ed.Fortaleza: EdUECE, 2015, v. 1, p. 03435-03446.

PAIS, J. Buscas de si: expressividades e identidades juvenis. In: ALMEIDA, M. I. M; EUGENIA, F. (Orgs.) Culturas jovens: novos mapas do afeto. Rio de Janeiro: Zahar, p. 07-24, 2006.

PEIRANO, M. Etnografia não é método. PEIRANO, M. Etnografia não é método.

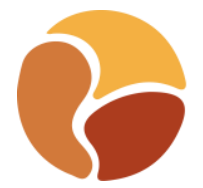


Horizontes Antropológicos, 20(42): 377-391, 2014.

PEREIRA-TOSTA, S. Antropologia e educação: culturas e identidades na escola. Magis, Revista Internacional de Investigación en Educación, 3 (6), 413-431, 2011.

PINAR, W. Estudos curriculares: ensaios selecionados. São Paulo: Cortez, 2016. 